\title{
Treat Diabetes Without Medicine
}

\section{Uqbah lqbal}

Faculty of Social Sciences and Humanities, UKM, Bangi Selangor, Malaysia

Corresponding author: Uqbah Iqbal, Faculty of Social Sciences and Humanities, UKM 43650, Bangi Selangor, Malaysia, Tel: 60389215555; Email: uqbah@siswa.ukm.edu.my

Received: 15 January 2017; Accepted: 20 January 2017; Published: 24 January 2017

Citation: Iqbah U. Treat Diabetes Without Medicine. Ann Clin Lab Res. 2017, 5: 1.

\section{Opinion}

Written by Raja Mohamed Kassim, this book is the third book of the author. In this book the authors explain the real facts, disease, and methods of treating diabetes without medication. When venturing into and examine the treatment of "Varma, Acutouch and Naturopathy", then the writer is aware that the human body does not need any medication to treat the disease and the body is able to treat the disease itself. When finished reading this book the reader will understand it. By adopting rules that are described in this book, diabetes can be treated completely without any medicine.

This book discuss, explains, and gives solutions for diabetes in adults, children, infants and pregnant women. This book not only focuses on diabetes but includes the entire human health. From hair loss to cancer of all human diseases can be treated with the methods described in this book. The authors also show that sugar is needed by the body, get rid of the excess sugar from the body, the right to eat and drink, methods of mind control stress, avoid stress methods, methods of treating diabetes, methods of eating and drinking the right.

Diabetes is a disease of the most popular and feared among Malaysians, especially the Malays and Indians. According to the International Diabetes Federation, 3.2 million Malaysians are certified having diabetes in 2014 . If we examine the health of the back platform of our ancestors; will we understand that diabetes does not exist in the past. If it does not exist does it mean sugar content in the body of our ancestors are all stable and normal ?. Not! Maybe some of those with high sugar content, but the high sugar content in the body is not known as a disease of the past. Native traditional medicine does not consider the excess sugar in the body as the disease, modern medicine only consider health disorders. If you study the rear platform of your ancestors or relatives of your ancestors, you will not see a cut leg due to diabetes. You will not find in a waste of internal organs due to diabetes.

The author does not intend to accuse, insult or degrade the image of any party or medicine but when the facts are real; authors must disclose and distribute. The author's purpose in writing this book is to provide enlightenment about diabetes and human health. This book is to serve as a guide, readers are cautioned not to make any decision to consider the content of this book. Think and consult with an expert before making any decisions. Readers are requested to read this book carefully, understand its contents and provide awareness of diabetes to family members and acquaintances. Readers are allowed to use the facts from this book to raise awareness about diabetes and general health of the human body. If readers do not understand the facts contained in this book, please contact the author for clarification. 